\title{
GEOGRAFIA E PESQUISA QUALITATIVA: um olhar sobre o processo investigativo ${ }^{1}$
}

GEOGRAPHY AND QUALITATIVE RESEARCH: a look over the investigative process

Vera Lúcia Salazar Pessôa Professora do Programa de Pós-Graduação em Geografia/UFG/Campus Catalão/

Membro do NEPSA

\begin{abstract}
Resumo
A geografia, ao longo de sua trajetória, tem contribuído para desvendar a realidade. Conceitos e categorias ora são resgatados e colocados em discussão, ora formulados para que a realidade geográfica deixe de ser vista apenas pelo lado da observação e descrição e passe a ser interpretada por outras técnicas de pesquisa, transportadas, muitas vezes, de outras áreas do conhecimento. Tanto a pesquisa quantitativa quanto a qualitativa têm sido importantes recursos para esta análise. E uma não exclui a outra. $\mathrm{O}$ importante é a definição, pelo pesquisador, dos instrumentos (as técnicas) a serem utilizados para responder às indagações propostas em consonância com o método de interpretação. Assim, o objetivo desse texto é estabelecer uma relação entre a geografia e a pesquisa qualitativa, considerando sua importância e retomada, mais especificamente, após a década de 1980.
\end{abstract}

Palavras-chave: Geografia. Pensamento geográfico. Pesquisa Qualitativa.

\begin{abstract}
Over the course of History, Geography has contributed to unveil reality. Concepts and categories have at times been retrieved and brought into discussion, and at times formulated so that the geographic reality would no longer be accessed only by means of observation and description, but would be interpreted through new research techniques, often imported from different fields of knowledge. Both qualitative and quantitative research have proved to be important resources for this analysis, and they are not mutually exclusive. What is important is that the researcher should define the tools (techniques) to be employed in finding answers to the questions posed in accordance with the interpretation method. Thus, the goal of this paper is to establish a connection between Geography and qualitative research, addressing its importance and its resumption, particularly after the 1980 s.
\end{abstract}

Keywords: Geography. Geographic thought. Qualitative research. 


\section{Introdução}

Refletir sobre geografia e pesquisa constitui um desafio que nos leva a pensar o que fizemos e o que temos feito desde que a geografia se institucionalizou como ciência no século XIX.

Nas rupturas epistemológicas da ciência geográfica, ou seja, Geografia Tradicional, (calcada sobre as bases do positivismo), Geografia Pragmática (com ênfase para Geografia Quantitativa e Geografia Sistêmica ou Modelística) e Geografia Crítica (calcada sobre as bases do materialismo histórico e dialético), como o método de pesquisa (o uso dos instrumentos/técnicas) para a coleta de dados foi e tem sido trabalhado para dar respostas às inquietações que originam a pesquisa?

Essas indagações mostram que a escolha do "caminho" metodológico é de responsabilidade do pesquisador e está em consonância com seus princípios filosóficos e posturas frente à realidade em que vive. O processo investigativo suscita olhares diferenciados de acordo com o propósito da pesquisa. Para responder o( s ) problema (s) proposto (s) em sua pesquisa, o pesquisador pode escolher como método de pesquisa o paradigma quantitativo ou qualitativo.

Assim, o objetivo desse texto é estabelecer uma relação entre a geografia e a pesquisa qualitativa, considerando sua importância e retomada, mais especificamente, após a década de 1980.

Para cumprir esse objetivo, organizamos o texto em três partes, além da introdução e considerações finais. Na primeira parte, o objetivo é mostrar como o conhecimento, a ciência e a pesquisa contribuem para desvendar a realidade. $\mathrm{Na}$ segunda, abordar a pesquisa qualitativa e sua retomada no pós 1980 nos trabalhos das ciências sociais e humanas. E na terceira parte, estabelecer uma relação entre a geografia e a pesquisa qualitativa e sua importância nos trabalhos científicos. 


\section{O conhecimento, a ciência e a pesquisa: o desvendar da realidade}

O homem, desde a sua forma mais primitiva de vida, sempre buscou o conhecimento. Por meio dele, aprendeu a desvendar a realidade do mundo. A aquisição desse conhecimento ocorre de formas diferenciadas e o caminho percorrido para se obter este conhecimento deve estar de acordo com o objetivo estabelecido. No que se refere ao conhecimento obtido por meio da pesquisa científica (conhecimento científico) para que o mesmo possa ser divulgado, há um caminho a ser percorrido. O ponto de partida é a formulação do problema "[...]quando pode ser resolvido com conhecimentos já produzidos ou com aqueles factíveis de serem produzidos" (GUIMARÃES, 2002, p.20).

Para compreender essa realidade (empírica), surgem os questionamentos para fundamentar o senso crítico que "[..] busca sua essência, seu verdadeiro significado. E sua explicação pode ser encontrada pelo emprego da ciência”(SEABRA, 2001, p.6).

A partir da necessidade de obter conhecimentos mais científicos do que aqueles oriundos do senso comum, desenvolveu-se a ciência. Esta surgiu para proporcionar respostas mais seguras aos problemas levantados, demonstrar a verdade dos fatos e possibilitar sua aplicação prática. Entre os pesquisadores, mesmo procurando entender a ciência por ângulos diferentes, há um consenso de que a pesquisa científica caminha para um objetivo comum que é chegar à verdade dos fatos, conforme já destacado. Portanto, "[..] fazer pesquisa é desenvolver um conjunto de atividades orientadas para a aquisição de determinado conhecimento"(SEABRA, 2001, p.19).

Nesse sentido, a "[..]ciência caracteriza-se por ser a tentativa do homem entender e explicar racionalmente a natureza, buscando formular leis que, em última instância, permitam a atuação humana" (ANDERY et al., 2003, p.13). Assim, ao 
formular as leis e as teorias, a ciência possibilita ampliar o conhecimento científico. Esse conhecimento científico, na análise de Demo (2000, p.13, grifos do autor), “é mais reconstruir do que construir conhecimento." O autor faz as seguintes considerações sobre o conhecimento e a pesquisa:

\begin{abstract}
modernas teorias da aprendizagem apontam para o caráter construtivo do conhecimento, em contraposição ao instrucionismo que insiste na simples transmissão reprodutiva. No entanto, podem exagerar na dose, quando supõem excessiva criatividade, como se partíssimos do nada. Na prática, conhecemos com base no que já está conhecido, aprendemos do que outros já aprenderam. Sobretudo nos ambientes escolares e universitários, por mais que seja essencial praticar a pesquisa como estratégia central de aprendizagem, dificilmente construímos conhecimento tipicamente novo. $\mathrm{O}$ que mais fazemos é retomar o conhecimento disponível e refazê-lo com mão própria. Entretanto, não se trata de procedimento adequado, quando apenas reproduzimos conhecimento [...] Reconstruir conhecimento significa, portanto, pesquisar e elaborar, impreterivelmente. Pesquisa é entendida tanto como procedimento de fabricação do conhecimento, quanto como procedimento de aprendizagem (princípio científico e educativo), sendo parte integrante de todo processo reconstrutivo de conhecimento. (DEMO, 2000, p.19, grifos do autor)
\end{abstract}

Nesse processo de "reconstrução" do conhecimento científico, tomando como referência a abordagem de Demo (2000), estamos nos apropriando do conhecimento elaborado para sua nova produção numa tentativa de conhecer e compreender o mundo que nos cerca.

Essa apropriação do conhecimento é explicada também por Cervo e Bervian (1977), Teixeira (2005) e Seabra (2001). Para Cervo e Bervian (1977, p.4), "pelo conhecimento, o homem penetra as diversas áreas da realidade para dela tomar posse". Teixeira (2005, p.79, grifos do autor) mostra que o "conhecimento seja ele qual for, representa, no cenário da vida, a apropriação da realidade, que é a totalidade das coisas conhecidas pelo sujeito. Conhecer, saber e ter conhecimento é apreender os seres e as coisas" (grifos do autor). Seabra (2001) explica que a apropriação é

o modo pelo qual é possível ao indivíduo compreender a realidade, podendose incluir na percepção humana toda a subjetividade e a mística presentes no mundo do imaginário. Em função da complexa realidade em que vivemos, o ato de conhecer não acontece da noite para o dia. É um processo longo em direção à descoberta da essência das coisas, nem sempre viáveis no mundo real [...] Conhecer a realidade não significa necessariamente desvendar a verdade de forma clara e transparente, mas parte dela [...] A explicação dos

Geo UERJ - Ano 14, no. 23, v. 1, $1^{\circ}$ semestre de 2012 p. 4-18

ISSN: 1415-7543 E-ISSN: 1981-9021

http://www.e-publicacoes.uerj.br/index.php/geouerj 
fenômenos materiais e sociais depende da maneira como ocorre a sua apropriação. (SEABRA, 2001, p.14-15).

A produção do conhecimento científico não é própria do homem contemporâneo. Desde as primeiras formas de organização social à sociedade atual, é possível identificar a constante tentativa do homem para compreender não só o mundo, mas a si próprio. Também é possível identificar a interrelação entre as necessidades humanas e o conhecimento produzido como marca comum aos diferentes momentos do processo de construção do conhecimento científico, isto é, as necessidades humanas vão se transformando a partir do conhecimento produzido ao mesmo tempo em que atuam como geradoras de ideias e explicações (ANDERY et al., 2003).

O processo de construção do conhecimento científico e seu produto refletem o desenvolvimento e a ruptura ocorridos nos diferentes momentos da história. Ou seja, os antagonismos presentes em cada modo de produção e as transformações de um modo de produção a outro são transpostos para as ideias científicas elaboradas pelo homem (ANDERY et al., 2003).

Ao fazer um paralelo dessa reflexão com a geografia verificamos que as rupturas epistemológicas foram importantes para repensar a realidade. $\mathrm{O}$ conhecimento produzido em cada momento histórico da ciência, como um todo, e da geografia de forma específica, estava ligado a todo um conjunto de valores, ideologias e concepções de homem e mundo. Assim, [...] transformar o mundo, criar objetos e concepções, encontrar explicações e avançar previsões, trabalhar a natureza e elaborar suas ações e ideias são subjacentes a todo esforço de pesquisa" (CHIZOTTI, 1991, p.11).

Nesse sentido, a geografia, ao longo de sua trajetória, tem contribuído para desvendar a realidade. Conceitos e categorias ora são resgatados e colocados em discussão, ora formulados para que a realidade geográfica deixe de ser vista apenas pelo lado da observação e descrição e passe a ser interpretada por outras técnicas de pesquisa transportadas, muitas vezes, de outras áreas do conhecimento. Tanto a pesquisa quantitativa quanto qualitativa têm sido importantes recursos para esta análise. E uma não exclui a outra. O importante é a definição, pelo pesquisador, dos instrumentos (as 
técnicas) a serem utilizados para responder às indagações propostas em consonância com o método de interpretação.

Assim, ao atuar sobre a realidade, o homem não age diretamente sobre a mesma. Entre ele e seus atos há sempre um instrumento. O mesmo acontece quando faz ciência, quando investiga cientificamente. Para fazer um trabalho científico é preciso conhecer os instrumentos (as técnicas) que se constituem de procedimentos metodológicos para alcançar os resultados de cunho científico, além da necessidade de imbuir-se do espírito científico (CERVO; BERVIAN, 1977).Os instrumentos, portanto, são "ferramentas" que ajudarão o pesquisador a definir se o trabalho terá uma abordagem sob a ótica quantitativa ou qualitativa.

Dessa forma, o embasamento teórico somado ao domínio do uso dos instrumentos possibilitará a confiabilidade e a aplicabilidade desse conhecimento construído para a interpretação do material empírico, sua organização e comunicação precisa dos resultados permitindo a validade científica.

\section{A pesquisa qualitativa: retomando uma discussão}

As mudanças de paradigmas na ciência, conforme já destacado, estão em sintonia com as transformações sociais, políticas, econômicas e ambientais da sociedade. De forma específica, na América Latina, as transformações ocorridas na década de 1970 levaram a educação, as ciências sociais e a ciências humanas a um repensar sobre a interpretação da realidade. A abertura política, ocorrida em quase todos os países latino americanos, ao final da década de 1970, fez reacender o paradigma qualitativo nas pesquisas iniciadas na década de 1980.

Ao falar sobre a importância da pesquisa qualitativa, Godoy (1995) mostra que ela ocupa um lugar significativo entre as várias possibilidades de se estudar os fenômenos que envolvem os seres humanos e suas intrincadas relações sociais estabelecidas em diversos ambientes. 
Nas pesquisas qualitativas, o pesquisador procura, na sua elaboração, seguir, de acordo com Alves-Mazzotti e Gewandsznajder (2002, p.131), a tradição compreensiva ou interpretativa: "as pessoas agem em função de suas crenças, percepções, sentimentos e valores [...] Seu comportamento tem sempre um sentido, um significado que não se dá a conhecer de modo imediato, precisando ser desvelado."

A escolha entre a pesquisa quantitativa e qualitativa deve ser feita a partir dos objetivos que se deseja alcançar, isto é, em benefício da pesquisa e não do pesquisador. Desse modo, para estudos complexos que não exigem a quantificação é mais pertinente o uso da pesquisa qualitativa que,

\begin{abstract}
por ser uma abordagem mais interpretativa que se propõe traduzir e expressar o fenômeno estudado, também se constitui em um trabalho laborioso, visto que é necessário registrar as informações, coletar dados, organizá-los e fazer as análises. (MATOS; PESSÔA, 2009, p.282).
\end{abstract}

Outro aspecto importante, ressaltado por Triviños (1987), é que por meio das informações coletadas e analisadas, é possível originar a exigência de novas buscas de dados. De acordo com o autor, isto ocorre

\begin{abstract}
porque o pesquisador não inicia seu trabalho orientado por hipóteses levantadas a priori cuidando de todas as alternativas possíveis, que precisam ser verificadas empiricamente, depois de seguir passo a passo o trabalho que, como as metas, tem sido previamente estabelecidos. As hipóteses colocadas podem ser deixadas de lado e surgir outras, no achado de novas informações, que solicitam encontrar outros caminhos. (TRIVIÑOS, 1987, p.131).
\end{abstract}

Para tanto, é necessário usar adequadamente os procedimentos e os instrumentos e saber fazer a interpretação. Nesse sentido, Alves-Mazzotti e Gewandsznajder (2002) mostram que

a confiabilidade e a aplicabilidade dos conhecimentos produzidos nas ciências sociais e na educação [e também na geografia, encarte nosso] depende da seleção adequada de procedimentos e instrumentos de interpretação cuidadosa do material empírico (ou de "dados"), de sua organização em padrões significativos da comunicação precisa dos resultados e conclusões e da validade destes através do diálogo com a comunidade científica. (ALVES-MAZZOTTI ; GEWANDSZNAJDER, 2002, p.146, destaque dos autores). 
$\mathrm{Na}$ pesquisa qualitativa, a problemática do tema é o eixo fundamental e norteador da pesquisa. A formulação do problema é a base empírica e fomenta a busca de um corpo teórico que deve orientar e contextualizar o objeto de estudo no tempo e no espaço (MATOS; PESSÔA, 2009). No desenvolvimento de um estudo de pesquisa qualitativa também são importantes a delimitação temporal e espacial. O recorte espacial refere-se "aos limites do espaço a ser estudado e onde se localiza o tema selecionado [...]. O recorte temporal refere-se ao momento do tempo no qual situa-se nosso tema espacialmente recortado" (CORRÊA, 2003, p.11-12).

Desse modo, na pesquisa qualitativa é importante a imersão do pesquisador no contexto de interpretar e interagir com objeto estudado e a adoção de postura teóricometodológica para decifrar os fenômenos. A ciência é dinâmica e está sempre em processo de mudança à procura de novos resultados. A importância de o pesquisador estar sempre atento a essa dinâmica da ciência é mostrada por Whitacker (2002, p.37) na seguinte reflexão: “[...]a ciência está em busca da explicação e do desvelamento de fatores que não estão claros para o conhecimento do senso comum e em geral o contrariam." Continuando sua reflexão, a autora mostra que "[...] se o pesquisador não se rodeia de cuidados especiais para colher e trabalhar os dados (sejam qualitativos ou quantitativos) corre o risco de fazer um bom trabalho, mas que poderia ser feito por qualquer bom repórter para o caderno de cultura do jornal de domingo" (WHITACKER 2002,p.37). Ao referir-se ao embasamento teórico e aos procedimentos, a autora destaca que além do sólido embasamento teórico é preciso utilizar os procedimentos rigorosamente controlados e experimentados que possibilitem confirmar e, se necessário, reformular as teorias (WHITACKER, 2002). Nessa linha de procedimento, é que teremos o avanço da ciência.

\section{A geografia e a pesquisa qualitativa: um caminho para a investigação}

Para entender a contribuição da pesquisa qualitativa nos trabalhos de Geografia é importante destacar o cenário mundial da década de 1960 e 1970. Dois acontecimentos começaram a preocupar os geógrafos: o crescimento desordenado e os custos sociais e

Geo UERJ - Ano 14, no. 23, v. 1, $1^{\circ}$ semestre de 2012 p. 4-18

ISSN: 1415-7543 E-ISSN: 1981-9021

http://www.e-publicacoes.uerj.br/index.php/geouerj 
políticos do capitalismo. Isto porque ficou evidenciado que, em escala mundial, o crescimento não havia beneficiado os países subdesenvolvidos e, em escala nacional e local, não havia corrigido e nem atenuado as diferenças sociais. O que ocorreu é que os programas desenvolvimentistas aumentaram as distâncias entre as condições de vida dos vários países. Em nível nacional, esses programas fizeram crescer a pobreza e a miséria, sobretudo nos países do Terceiro Mundo $^{2}$, tornando inviáveis as condições de vida nas grandes cidades. Ao mesmo tempo em que o uso de tecnologias avançadas aumentava a renda das grandes empresas, esse "progresso" acelerava o processo de destruição e degradação do meio ambiente (ANDRADE, 1987).

Nesse momento histórico, há uma "crise" na ciência. Na geografia, tivemos o movimento de renovação (a Geografia Pragmática e a Geografia Crítica), diante da crise da Geografia Tradicional em meados da década de 1950, crise que se desenvolveu aceleradamente nos anos seguintes.

Ao falar sobre as crises, emergências das teorias científicas e resposta à crise científica, Khun (1975, p.115) mostra que o "significado das crises consiste exatamente no fato de que indicam que é chegada a ocasião para renovar os instrumentos." Para o autor, "as crises são uma pré-condição necessária para a emergência de novas teorias" (KHUN,1975, p.107). Nesse sentido, o autor pergunta: "como os cientistas respondem à sua existência"?(KHUN, 1975, p.107). A resposta às crises é o surgimento de um novo paradigma. "Decidir rejeitar um paradigma é sempre decidir simultaneamente aceitar outro e o juízo que conduz a essa decisão envolve a comparação de ambos os paradigmas com a natureza, bem como sua comparação mútua” (KHUN, 1975, p.108, grifo do autor).

Assim, "uma crise pode terminar com a emergência de um novo candidato a paradigma e com subseqüente batalha para sua aceitação"(KHUN, 1975, p.116). Sobre a transição e emergência de um paradigma, o referido autor, em sua análise, faz a seguinte menção:

\footnotetext{
a transição de um paradigma em crise para um novo, do qual pode surgir uma nova tradição de ciência normal, está longe de ser um processo cumulativo 
obtido do velho paradigma. É antes uma reconstrução da área de estudos a partir de novos princípios, reconstrução que altera algumas das generalizações teóricas mais elementares do paradigma, bem como muitos de seus métodos e aplicações [...] Um novo paradigma emerge [...] antes que uma crise esteja bem desenvolvida ou tenha sido explicitamente reconhecida. (KHUN, 1975, p.116-117).

A análise de Khun (1975) serve para refletir sobre a mudança de paradigmas que ocorreu na ciência geográfica. A Geografia Tradicional, cujas análises eram feitas com base na observação, descrição e representação dos fatos, não conseguia mais explicar a realidade tanto mundial, quanto brasileira face às mudanças que estavam ocorrendo no campo político, econômico, social e educacional, conforme já destacado.

As principais mudanças podem ser assim definidas: a expansão do capitalismo monopolista; o planejamento econômico e o territorial já se definiam sob a ação do Estado, interferindo na organização do espaço; a urbanização se expandia de forma acelerada; no campo, a industrialização e a mecanização das atividades agrícolas em várias partes do mundo se concretizavam no fenômeno da modernização da agricultura; o êxodo rural, em função da modernização do campo, contribuía para o crescimento das cidades.

Diante desse quadro, o instrumento de pesquisa da Geografia tornou-se defasado implicando em uma crise das técnicas tradicionais de análise. Estas não davam mais conta nem da descrição, nem da representação dos fenômenos da superfície terrestre. Com isto, surgiu também uma crise de linguagem, isto é de metodologia de pesquisa. (MORAES, 1981). Novos instrumentos como o sensoriamento remoto, as imagens de satélite, o computador substituíram os trabalhos de campo, característicos da Geografia Tradicional. Portanto, havia uma "crise" tanto no método de interpretação quanto no método de pesquisa. A resposta a essa crise, conforme apontou Khun (1975), foi a emergência de um novo paradigma.

Assim, a Geografia Tradicional, fundamentada no positivismo clássico, não mais respondia às inquietações que a realidade apresentava. A resposta a essa "crise" científica foi o movimento de Renovação da Geografia. Consideramos, no movimento 
de Renovação da Geografia, dois paradigmas importantes, já destacados: a Geografia Pragmática e a Geografia Crítica.

A renovação pragmática na Geografia, mais conhecida como Nova Geografia (New Geography), utilizou-se da quantificação, apoiada no uso de métodos matemáticos, o uso dos modelos de representação e explicação ao trabalhar temas geográficos e a aplicação da Teoria dos Sistemas. No Brasil, a Nova Geografia, como foi denominada, se consolidou como um novo paradigma para atender aos interesses políticos do país a partir do Golpe Militar de 1964 até a abertura política que se iniciou em 1978.

Nessa ótica de análise, a nova proposta para explicar a realidade brasileira se legitimou como verdade e a partir daí o pesquisador em geografia passou a se preocupar mais com a "aparência" do que com a "essência" dos fatos.

Entretanto, ao final da década de 1970, a preocupação apenas com a "aparência", ou seja, o "visível, a variabilidade das formas, o lugar - preocupações eminentemente geográficas" (ABREU, 1989, p.20) não era mais suficiente para explicar a realidade. Foi necessário ir "mais a fundo" na busca de respostas aos problemas detectados, ou seja, a "essência" da realidade política, social, econômica e educacional teria que ser desvendada. Rompia-se com o paradigma da Geografia Pragmática para dar lugar à Geografia Crítica.

Assim, a procura por "novos caminhos" teórico-metodológicos levou o geógrafo a redefinir o método de pesquisa (MORAES; COSTA, 1984). Em seus trabalhos, o geógrafo retomou técnicas de pesquisas já utilizadas, como por exemplo, o trabalho de campo e a observação e acrescentou outras como a entrevista, a história oral, a pesquisaparticipante, a pesquisação, o estudo de caso, a análise do discurso, o diário de campo. "Novas trilhas" surgiram para a investigação geográfica. Um "novo" olhar metodológico possibilitou ao geógrafo compreender "as causas da crise e procurar caminhos que fossem à raiz dos problemas" (ANDRADE, 1987, p.112). 
Para interpretar a realidade com esse "novo" olhar teórico, a fenomenologia e a dialética serão as orientações filosóficas que permitirão o uso da pesquisa qualitativa nos trabalhos como reação ao enfoque positivista. Portanto, o domínio do conteúdo e das técnicas são importantes para a construção desse conhecimento.

O pesquisador, ao apresentar os resultados de sua pesquisa à sociedade, mostra que esta se torna um importante instrumento de disseminação do conhecimento. Por meio dos resultados alcançados, será possível compreender a realidade e se posicionar criticamente frente a ela; propor a transformação da sociedade porque é parte de seu compromisso político; propor discussões e até mesmo soluções para o problema que originou a pesquisa; fazer com que as ideias e conclusões sejam ouvidas por um número significativo de pessoas.

\section{Considerações Finais}

Ao longo do processo histórico da ciência, as transformações sociais, políticas e econômicas contribuíram para gerar as "crises". Estas, dentre elas, a científica, são importantes porque permitem refletir sobre o sujeito, o objeto, o conteúdo, as técnicas usadas nas pesquisas. A opção teórico-metodológica e o tipo de pesquisa, qualitativa ou quantitativa, refletem a postura filosófica do pesquisador.

A busca por "novos" caminhos mostra que a ciência é dinâmica e que o conhecimento se produz a partir da interdisciplinaridade/multidisciplinaridade com as áreas afins. Essa integração entre diferentes conhecimentos possibilita criar saberes diferenciados e importantes para a construção do conhecimento.

Na Geografia, a "revolução" teórico-metodológica, iniciada na década de 1960, marcou a ruptura com a Geografia Clássica. "Novos" olhares surgiram para trabalhar a realidade, quer do ponto de vista do conteúdo, quer do ponto de vista das técnicas. A interdisciplinaridade muito contribuiu para esse momento de transformações. A essência da realidade passou a ter um outro viés interpretativo à luz de posicionamentos filosóficos e políticos do pesquisador. Esse movimento de renovação abriu novas 
perspectivas para o geógrafo trabalhar o seu objeto de estudo e uma busca constante por linhas teóricas e procedimentos que pudessem explicar as contradições do desenvolvimento desigual da sociedade.

\footnotetext{
${ }^{1}$ Texto apresentado no V Encontro de Grupos de Pesquisa - 25 a 27 de novembro/2009 -UFSM/ Santa Maria (RS) na conferência de abertura: "Olhares sobre o processo investigativo."

${ }^{2}$ A expressão Terceiro Mundo é muitas vezes substituída por Países do Sul, por oposição aos países do Norte considerados mais ricos e dominantes. Para além deste termo, é comum o uso de expressões como Países Subdesenvolvidos, Países em vias de desenvolvimento ou ainda Países Emergentes. Aplicam-se, geralmente, às nações pobres da América Latina, África e Ásia (FERREIRA, Ana Cristina. Terceiro Mundo: comércio livre, comércio justo ou protecionismo. www.ciari.org. set.2006. p.4.
}

AGRADECIMENTOS: Agradecemos à Profa. Dra. Estevane de Paula Pontes Mendes e ao Prof. Dr. Glaucio José Marafon pela leitura e sugestões.

\section{Referências}

ABREU, Maurício A. Reflexões sobre algumas críticas da geografia crítica. In; ENCONTRO ESTADUAL DOS PROFISSIONAIS DE GEOGRAFIA, I., 1989, Uberlândia. Anais... Conferências e Mesas-Redondas. Uberlândia: AGB-Seção Uberlândia, 1989. p.15-25.

ALVES-MAZZOTTI, Alda J.; GEWANDSZNAJDER, Fernando. O método nas ciências naturais e sociais: pesquisa quantitativa e qualitativa. 2.ed. São Paulo: Pioneira Thomson Learning, 2002.

ANDERY, Maria Amália. et al. Introdução: olhar para a história: caminho para a compreensão da ciência hoje.In: (Org.). Para compreender a ciência: uma perspectiva histórica. 12.ed. Rio de Janeiro: Garamond; São Paulo:EDUC, 2003. p.1015.

ANDRADE, Manuel C. de. Geografia, ciência da sociedade: uma introdução à análise do pensamento geográfico. São Paulo: Atlas, 1987.

BACHELARD, Gaston. Conhecimento comum e conhecimento científico. Tempo Brasileiro, Rio de Janeiro, 2.ed., n.28, p.27-46, jan./mar. 1972

CERVO, Amado L.; BERVIAN, Pedro A. Metodologia científica: para uso dos estudantes universitários. 2.ed. rev. ampl. São Paulo: McGraw-Hill do Brasil, 1977.

CHIZOTTI, Antonio. Pesquisa em ciências humanas e sociais. São Paulo: Cortez, 1991 (Biblioteca da Educação. Serie 1, Escola; v.16).

CORRÊA, Roberto L. Análise crítica dos textos geográficos: breves notas. GeoUERJ, Rio de Janeiro, n.14, p.7-18, 2. Semestre de 2003. 
DEMO, Pedro. Metodologia do conhecimento científico. São Paulo: Atlas, 2000.

GOMES, Paulo César da C. O advento dos tempos modernos. In:__Geografia e modernidade. 2.ed. Rio de Janeiro: Bertrand Brasil,2000. p.247- 337.

GODOY, Arilda S. Pesquisa qualitativa: tipos fundamentais. Revista de Administração de Empresas, São Paulo, v.35, n.3, p.20-29, maio/jun.1995.

FERNANDES, Aliana; GUIMARÃES, Flávio R.; BRASILEIRO, Maria do Carmo E. (Org.). O fio que une a pedras: a pesquisa interdisciplinar na pós-graduação.São Paulo: Biruta, 2002.

GUIMARÃES, Flávio R. Um novo olhar sobre o objeto da pesquisa em face da abordagem interdisciplinar. In: FERNANDES, Aliana; GUIMARÃES, Flávio R.; BRASILEIRO, Maria do Carmo E. (Org.). O fio que une a pedras: a pesquisa interdisciplinar na pós-graduação.São Paulo: Biruta, 2002. p.13-25

KHUN, Thomas S. A estrutura das revoluções científicas. Tradução de Beatriz Vianna Boeira e Nelson Boeira. Revisão de Alice Kyoto Miyashiro. São Paulo: Perspectiva, 1975.

MATOS, Patrícia F.; PESSÔA, Vera L. S. Observação e entrevista: construção de dados para a pesquisa qualitativa em geografia agrária. In: RAMIRES, Julio C. de L. ; PESSÕA, Vera L. S (Org.). Geografia e pesquisa qualitativa: nas trilhas da investigação. Uberlândia: Assis Editora, 2009. p.279-291.

MORAES, Antonio C. R. Geografia: pequena história crítica. São Paulo: HUCITEC, 1981.

MORAES, Antonio C. R.; COSTA, Wanderley M. da. Geografia crítica: a valorização do espaço. São Paulo: HUCITEC, 1984.

MOREIRA, Ruy (Org.). Geografia: teoria e crítica: o saber posto em questão. Petrópolis: Vozes, 1982.

PÁDUA, Elisabete M. M. de. Metodologia da pesquisa: abordagem teórico-prática. 8.ed. Campinas: Papirus,2002.

PESSÔA, Vera Lúcia S. Grupos de pesquisa e formação dos profissionais em geografia agrária. In: ENCONTRO DE GRUPOS DE PESQUISA, I., 2005, Rio de Janeiro. Anais... Rio de Janeiro: UERJ, 2005. 1 CD-ROM.

PESSÔA, Vera Lúcia S. Entre o rural e o urbano: construindo grupos de pesquisa. In: ENCONTRO DE GRUPOS DE PESQUISA, II., 2006, Uberlândia. Anais... Uberlândia: UFU/IG/LAGEA, 2006. 1CD-ROM. 
PESSÔA, Vera Lúcia S. Pesquisa e conhecimento: construindo os "saberes"... Dialogus, Ribeirão Preto, v.1, n.2, p.15-27, 2006.

PESSÔA, Vera Lúcia S. A nova geografia e o (re) pensar teórico-metodológico sobre o espaço brasileiro. In: COLÓQUIO BRASILEIRO HISTÓRIA DO PENSAMENTO GEOGRÁFICO, I., 2008. Uberlândia, Anais... Uberlândia: UFU, 2008. 1 CD-ROM.

SANTOS, Antonio R. dos. Metodologia científica: a construção do conhecimento. 5.ed.rev. Rio de Janeiro: DP\&A, 2002.

SEABRA, Giovanni de F. Pesquisa cientifica: o método em questão. Brasília: Editora da UnB, 2001.

SPOSITO, Eliseu S. A questão do método e a crítica do conhecimento. In:__. Geografia e filosofia: contribuição para o ensino do pensamento geográfico. São Paulo: Editora da UNESP, 2004. p.24-72.

TEIXEIRA, Elisabeth. Segunda metodologia. In: As três metodologias: acadêmica, da ciência e da pesquisa. Petrópolis: Vozes, 2005. p.79-93. item: 2.1 Conhecimento e ciência.

TRIVIÑOS, Augusto N. S. Pesquisa qualitativa. In: ___.Introdução à pesquisa em ciências sociais: a pesquisa qualitativa em educação. São Paulo: Atlas, 1987. p.117173.

Artigo encaminhado para publicação em maio de 2012.

Artigo aceito para publicação em junho de 2012. 